\title{
Treatment of Wastewater from a Dairy Industry Using Rice Husk as Adsorbent: Treatment Efficiency, Isotherm, Thermodynamics, and Kinetics Modelling
}

\author{
Uttarini Pathak, Papita Das, Prasanta Banerjee, and Siddhartha Datta \\ Department of Chemical Engineering, Jadavpur University, Kolkata 700032, India \\ Correspondence should be addressed to Uttarini Pathak; uttarini1212@gmail.com
}

Received 24 September 2015; Revised 16 December 2015; Accepted 24 December 2015

Academic Editor: Perla B. Balbuena

Copyright (C) 2016 Uttarini Pathak et al. This is an open access article distributed under the Creative Commons Attribution License, which permits unrestricted use, distribution, and reproduction in any medium, provided the original work is properly cited.

\begin{abstract}
Effluent from milk processing unit contains soluble organics, suspended solids, and trace organics releasing gases, causing taste and odor, and imparting colour and turbidity produced as a result of high consumption of water from the manufacturing process, utilities and service section, chemicals, and residues of technological additives used in individual operations which makes it crucial matter to be treated for preserving the aesthetics of the environment. In this experimental study after determination of the initial parameters of the raw wastewater it was subjected to batch adsorption study using rice husk. The effects of contact time, initial wastewater concentration, $\mathrm{pH}$, adsorbent dosage, solution temperature and the adsorption kinetics, isotherm, and thermodynamic parameters were investigated. The phenomenon of adsorption was favoured at a lower temperature and lower $\mathrm{pH}$ in this case. Maximum removal as high as $92.5 \%$ could be achieved using an adsorbent dosage of $5 \mathrm{~g} / \mathrm{L}, \mathrm{pH}$ of 2 , and temperature of $30^{\circ} \mathrm{C}$. The adsorption kinetics and the isotherm studies showed that the pseudo-second-order model and the Langmuir isotherm were the best choices to describe the adsorption behavior. The thermodynamic parameters suggested that not only was the adsorption by rice husk spontaneous and exothermic in nature but also the negative entropy change indicated enthalpy driven process.
\end{abstract}

\section{Introduction}

Dairy industry, one of the largest types of food industry, contributes to a great extent to pollution with pollutants being organic in nature normally consisting of $1 / 3$ dissolved, $1 / 3$ colloidal, and $1 / 3$ suspended substances, while inorganic materials are usually present mainly in solution [1]. Considering the ever increasing demand for milk, the dairy industry in India arises as the largest industry to have the maximum waste generation and related environmental problems are of increasing importance. Thus the rapid growth of industries has not only enhanced the productivity but also resulted in the release of toxic substances into the environment, creating health hazards and hampering the normal activity of flora and fauna. The dairy industry converts the raw milk into various products like butter, cheese, yogurt, and processed milk as condensed milk and dried milk (milk powder) involving processes such as chilling, pasteurization, and homogenization. Water is used in all processes in the dairy industry in the ratio of 1:10 (water:milk) per liter of milk [2], containing high concentration of organic materials, and all these components contribute largely towards their high values of biological oxygen demand (BOD), inflated rates of chemical oxygen demand (COD), high concentration of suspended solids and oil greases, liquid effluents, and slurries containing a spectrum of large quantities of casein, lactose, and fats in addition to inorganic salts, besides detergents, sanitizers, and so forth used for washing [3]. The volume of the wastewater produced depends largely on the quantity of milk processed and type of product manufactured. It appears white in colour with heavy black sludge and strong butyric acid odors due to the decomposition of casein [4]. It is slightly alkaline in nature and becomes acidic quite rapidly, because of the fermentation of milk sugar to lactic acid. The COD of dairy wastewater is mainly due to milk, cream, or whey. Casein and whey are the main components of dairy wastewater which are relatively hydrophobic, making it poorly soluble in water, and have a negative charge in milk. The casein micelles exist in milk as a 
very stable colloidal dispersion and held together by calcium ions, inorganic phosphate, citrate ions:

$$
\begin{array}{cc}
\mathrm{H}_{2} \mathrm{~N}-\mathrm{R}-\mathrm{COO}^{-}+\mathrm{H}^{+} \longrightarrow & { }^{+} \mathrm{H}_{3} \mathrm{~N}-\mathrm{R}-\mathrm{COO}^{-} \\
\text {Casein Micelle } & \text { Acid Casein } \\
\text { Colloidal dispersion } & \text { Insoluble Particles }
\end{array}
$$

Therefore all the above-mentioned phenomena make dairy industry, like many others, challenged with rising costs for wastewater treatment and disposal. Moreover industries have to meet the discharge standards mentioned by CPCB which becomes a great problem for the industrialists.

Technologies such as coagulation/flocculation process and oxidation process have been developed over the years to remove organic matter (expressed as chemical oxygen demand, COD) from industrial wastewater. These methods are effective in fields of reduction and time but are expensive and require skilled personnel. They also become disadvantageous in terms of $\mathrm{pH}$ adjustment and generation of chemical sludge that must be treated before disposal [5]. In addition to these various treatments which are already present in the dairy industry there are biological treatments including trickling filters and activated sludge process. Though they are effective for complete treatment of the wastewater but are noneconomical, large power demand, more chemical consumption, and large area availability. Thus it is very much necessary for characterization of wastewater, treatability studies, and planning of proper units and processes for effluent treatment.

Adsorption technique emerges as promising technique in the removal efficiency (COD) economy and operation [6]. Physical adsorption using activated carbon is effective in removal but has a high initial cost, low adsorption capacities, and separation inconvenience and needs a costly regeneration system [7]. All these have simulated the search of cheaper alternatives and application of biosorption in environmental treatment has become a significant research area in the past years. It is widely recognized that biosorption provides a feasible technique for the removal of pollutants from wastewater. Biosorption may be defined as a process wherein a solute molecule is removed from the liquid phase in contact with a solid, usually an inexpensive adsorbent which has a special affinity for the solute particles [8]. To explore these novel adsorbents, the use of biosorbents from numerous agroindustry wastes has received much attention and led to a constructive approach.

Rice husk which is the protective outer shell of the rice grain is abundantly obtainable as a by-product of the rice milling industries. It has been estimated that the annual production of rice husk is estimated to be around 120 million tonnes [9], constituting about one-fifth part of the total annual rice production throughout the world [10]. Thus the disposal becomes a crucial factor. The composition of rice husks is found to consist of about $32 \%$ cellulose, $21 \%$ hemicelluloses, $21 \%$ lignin, $20 \%$ silica, and 3\% crude protein [11]. Moreover their granular structure containing abundant floristic fiber, insolubility in water, chemical stability, and high mechanical strength make them potential adsorbent. They also consist of functional group such as carboxyl, hydroxyl, and amidogen, representing a favourable characteristic of rice husk [12].

However the application of plant wastes as adsorbents can also bring several problems such as high chemical oxygen demand (COD) and biological chemical demand (BOD) as well as total organic carbon (TOC) due to release of soluble organic compounds contained in the plant materials. Silica present on the external surface of rice husks in the form of silicon-cellulose membrane is responsible for insufficient binding between functional groups existing on rice husk surfaces and adsorbate ions or molecules present in solution. Presence of wax and natural fats on the internal surface of rice husk as impurities has also got impact on the adsorption properties of rice husk chemically and physically [12].

In this study the potential ability of rice husk without any modification as biosorbent for the adsorption of organic pollutants from dairy wastewater was investigated. The effects of initial concentration, $\mathrm{pH}$, adsorbent dosage, solution temperature on adsorption, and the adsorption kinetics, isotherms, and thermodynamic parameters were studied.

\section{Materials and Methods}

Wastewater sample was collected from outfall of a dairy industry at Dankuni near Durgapur Express Highway. Wastewater sample collected from the plant was placed in containers to be transported to the laboratory and stored at $4^{\circ} \mathrm{C}$ in a refrigerator. All the initial parameters of the wastewater were analysed in the laboratory as per the given standard methods in the handbook [13]. All the chemicals were of analytical reagent grades and used as received, without further purifications.

2.1. Adsorbent Preparation. The rice husk used was obtained from a nearby rice mill in Dankuni, West Bengal, India. It was washed repeatedly with double-distilled water to remove dust and soluble impurities, and this was followed by drying at $343 \mathrm{~K}$ for $24 \mathrm{~h}$. It was sieved using meshes to get the desired adsorbent size of 30 micrometers and stored in an air tight container.

2.2. Experimental Batch Study. The biosorption studies were carried out in $250 \mathrm{~mL}$ glass-stoppered, Erlenmeyer flasks containing a fixed amount of adsorbent. Solution $\mathrm{pH}$ was adjusted with $\mathrm{HCl}$ or $\mathrm{NaOH}(0.1 \mathrm{~N})$. $\mathrm{pH}$ had been measured by following electrometric method using a digital $\mathrm{pH}$ meter. A known amount of adsorbent was added to samples and was agitated at $150 \mathrm{rpm}$ agitation speed, allowing sufficient time for adsorption. Then, the mixtures were centrifuged and filtered through filter paper and the final concentration was determined in the filtrate using UV/VIS spectrophotometer. The effects of various parameters on the percentage removal were observed by varying adsorbent dosage (4, 6, 8 , and $10 \mathrm{~g} / \mathrm{L})$, initial $\mathrm{pH}$ of wastewater $(2,4,6,8$, and 10$)$, temperature $(293 \mathrm{~K}, 298 \mathrm{~K}, 308 \mathrm{~K}$, and $313 \mathrm{~K})$, and concentration $(183 \mathrm{mg} / \mathrm{L}, 195.4 \mathrm{mg} / \mathrm{L}, 207.4 \mathrm{mg} / \mathrm{L}, 219.6 \mathrm{mg} / \mathrm{L}$, and 
TABLE 1: Characteristics of dairy wastewater.

\begin{tabular}{lc}
\hline Initial parameters of wastewater & \\
\hline COD & $468 \mathrm{mg} / \mathrm{L}$ \\
BOD & $210 \mathrm{mg} / \mathrm{L}$ \\
Oil and grease & $240 \mathrm{mg} / \mathrm{L}$ \\
Chloride & $136 \mathrm{mg} / \mathrm{L}($ less than $250 \mathrm{ppm})$ \\
Alkalinity & $462.5 \mathrm{mg} / \mathrm{L} \mathrm{CaCo}$ equivalent \\
pH & $7.34-7.38$ \\
TSS & $942 \mathrm{mg} / \mathrm{L}$ \\
TDS & $680 \mathrm{mg} / \mathrm{L}$ \\
Conductivity & $1200 \mathrm{mS} / \mathrm{cm}$ \\
\hline
\end{tabular}

$231.8 \mathrm{mg} / \mathrm{L}$ ). The adsorption capacity was measured by the following equation:

$$
q_{e}=\frac{\left(C_{o}-C_{t}\right) V}{m},
$$

where $C_{o}$ is initial concentration $(\mathrm{mg} / \mathrm{L}), C_{t}$ is concentration at time $t(\mathrm{mg} / \mathrm{L}), V$ is the volume $(\mathrm{L})$ of wastewater, and $m$ is mass of biosorbent (g).

\section{Results and Discussions}

3.1. Characterization of Wastewater. The dairy wastewater collected from the local industry had the following characteristics presented in Table 1 . Various physicochemical parameters with whitish effluents along with unpleasant odor were observed. The results showed that though the wastewater did not have a very high COD value it was above the permissible limit. The COD value was found to be larger than the BOD value suggesting that the organic compounds in wastewater are slowly biodegradable [2]. The $\mathrm{pH}$ was found to be slightly alkaline in the range of 7.34-7.38. The chlorides may be present due to the use of detergents and sanitizers in the cleaning of equipment but the value was not above the permissible value. Oil and grease were high due to presence of fats, lactose, and proteins with a value of $240 \mathrm{mg} / \mathrm{L}$. The amounts of total suspended solids and total dissolved solids were quite high with values of $942 \mathrm{mg} / \mathrm{L}$ and $680 \mathrm{mg} / \mathrm{L}$. The presence of calcium ions as a prime constituent of casein was indicated by the high value of alkalinity of $462.5 \mathrm{mg} / \mathrm{L} \mathrm{CaCO}_{3}$ equivalent. Electrical conductivity of the wastewater was also recorded to be quite high.

\subsection{Batch Adsorption Study}

3.2.1. Effect of Adsorbent Dosage. The experiments were done under the conditions of constant temperature $\left(30^{\circ} \mathrm{C}\right)$, agitation speed $(150 \mathrm{rpm})$, constant $\mathrm{pH}$ of 7.38 , and variable adsorbent dosage $(4,6,8$, and $10 \mathrm{~g} / \mathrm{L})$. The adsorbent dosage was varied and the percentage removal as a function of adsorbent dosage was calibrated in Figure 1(a). It was observed that the percentage removal was found to be decreasing with increase in dosage. This increase in COD value may be due to the release of soluble organic compounds contained in the plant materials. The reduction was quite steep up to $8 \mathrm{~g} / \mathrm{L}$ after which there was no further reduction up to $10 \mathrm{~g} / \mathrm{L}$. It is to be noted that experiments were done for dosage beyond $10 \mathrm{~g} / \mathrm{L}$ but there was no further change for adsorption or desorption. These biosorbent materials are highly pervious in nature, but the porous volume is associated with numerous minute pores causing additional diffusional resistance that causes decrease in removal $[7,14,15]$.

3.2.2. Effect of $p H$. In biosorption studies $\mathrm{pH}$ of the solution is the most important factor influencing the process depicted in Figure 1(b). It influences not only the surface charge of the biosorbent but also the degree of ionization of the organic substances present in the solution and the dissociation of functional groups on the active sites of the sorbent. In this study the $\mathrm{pH}$ was varied between 2 and 10 from highly acidic range to high alkaline range keeping other parameters like adsorbent dosage at $5 \mathrm{~g} / \mathrm{L}$, temperature of $30^{\circ} \mathrm{C}$, and rotational speed of $150 \mathrm{rpm}$. The removal was favoured at a lower $\mathrm{pH}$ and there is a sharp decrease in the percentage removal with increase of $\mathrm{pH}$. This shows that organic removal is favoured at lower $\mathrm{pH}$. Due to dissociation of functional groups at higher $\mathrm{pH}$ the adsorbent surface carries a net negative charge while at lower $\mathrm{pH}$ it carries a net positive charge [16]. At low $\mathrm{pH}$ values, the rice husk surface would be protonated and became positive, and the surface will be surrounded by the hydrogen ions, which enhances the interactions between the organic substances and binding sites through attractive forces. On the other hand the casein has a negative charge in milk and water, resulting in electrostatic repulsion due to the reduction of electrostatic force of attraction between the oppositely charged adsorbate molecules and the binding adsorbent sites in alkali medium.

3.2.3. Effect of Temperature. Figure 1(c) displays the effect of variation of temperature on the adsorption process keeping other parameters same as before (like adsorbent dosage at $5 \mathrm{~g} / \mathrm{L}, \mathrm{pH}$ of 7.38 , and rotational speed of $150 \mathrm{rpm}$ ) and the temperature was varied between $20^{\circ} \mathrm{C}$ and $40^{\circ} \mathrm{C}$. The percentage removal decreased with increasing temperature. Due to weakening of the bonds between the adsorbate molecules and the active binding sites of the biosorbent the binding capacity decreases with increasing temperature [17]. Since the sorption potential of the adsorbent was greater at lower temperature, it can also be said that the sorption might be an exothermic process. With regard to the effect of temperature on the adsorption, an increasing uptake of organic molecules is expected when the adsorption temperature decreases because adsorption is a spontaneous process.

3.2.4. Effect of Concentration. The concentration of the wastewater was varied by the method of dilution keeping the other parameters same as above (adsorbent dosage at $5 \mathrm{~g} / \mathrm{L}, \mathrm{pH}$ of 7.38 , temperature of $30^{\circ} \mathrm{C}$, and rotational speed of $150 \mathrm{rpm})$. It was observed that on increasing the dilution or reducing the concentration the percentage removal increased. It is evident from Figure 1(d) that removal efficiency decreases slightly with the increase in initial 


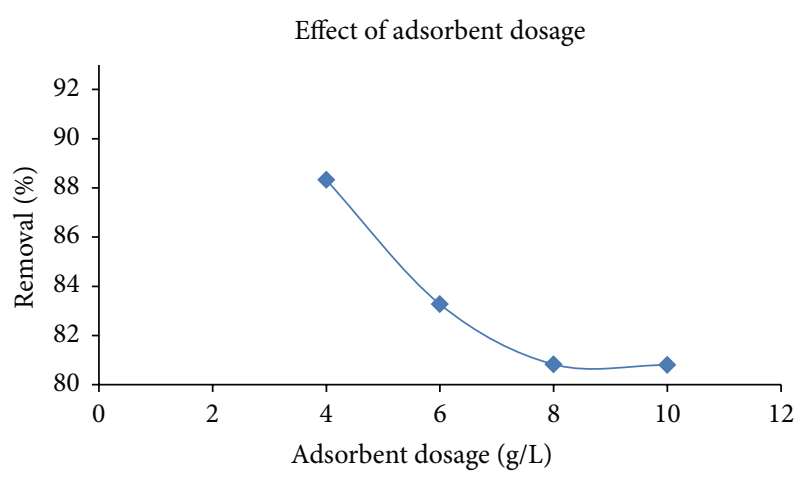

(a)

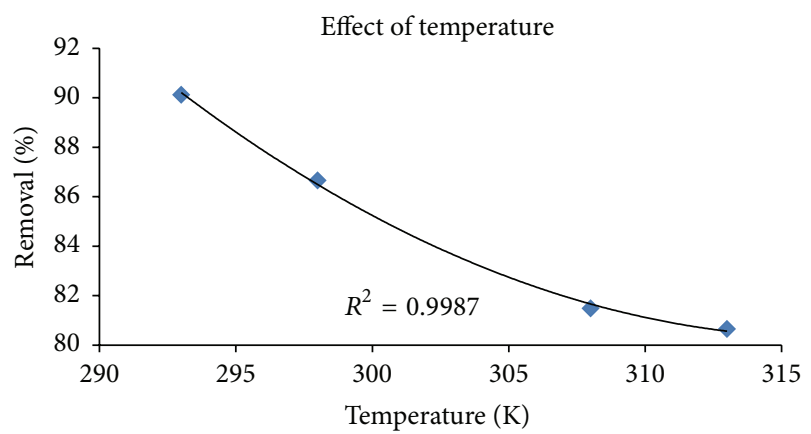

(c)

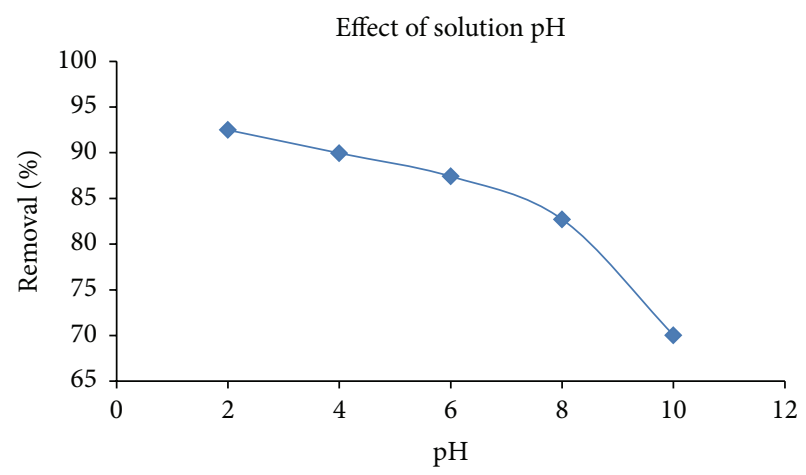

(b)

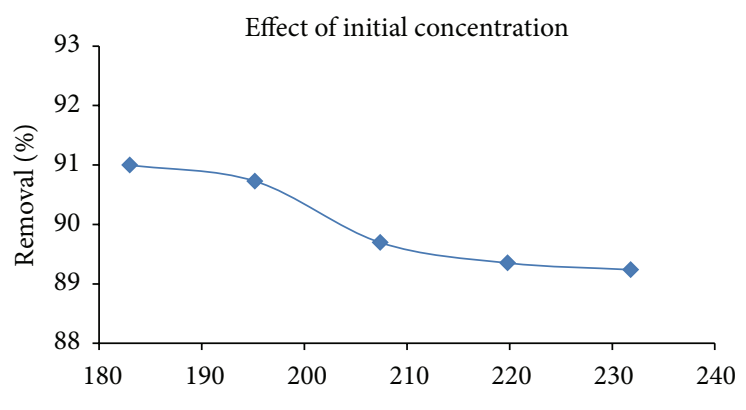

(d)

FIGURE 1: (a) Effect of adsorbent dosage on percentage removal by rice husk. (b) Effect of solution pH on percentage removal by rice husk. (c) Effect of temperature on percentage removal by rice husk. (d) Effect of initial concentration on percentage removal by rice husk.

concentration between 195.2 and $207.4 \mathrm{mg} / \mathrm{L}$ after which it remains almost constant indicating saturation of the sites. The phenomenon may be traced back to the reason due to the interference between binding sites at higher concentrations or inadequacy of solutes on solution with respect to available binding sites. Also in case of lower concentrations, the ratio of the initial number of moles of ions to the available surface area of adsorbent is large and subsequently the fractional adsorption becomes independent of initial concentration. However, at higher concentrations, the available sites of adsorption become fewer, and hence the percentage removal decreases [18].

3.3. Adsorption Isotherm. In the present study the adsorption behavior was investigated since isotherms like Langmuir and Freundlich provide the most important piece of information in understanding the adsorption process. They give some idea about the underlying sorption mechanism as well as the surface affinity and properties of the sorbent [19]. The equation is stated as follows:

$$
\frac{C_{e}}{q_{e}}=\frac{1}{K_{L} Q_{o}}+\frac{C_{e}}{Q_{o}},
$$

where $C_{e}$ is the equilibrium concentration, $q_{e}$ is the amount of ions or molecules adsorbed ( $\mathrm{mg} / \mathrm{g}), Q_{o}$ is $q_{e}$ for a complete monolayer $(\mathrm{mg} / \mathrm{g})$, and $K_{L}$ is sorption equilibrium constant. A plot of $C_{e} / q_{e}$ versus $C_{e}$ should indicate a straight line of slope $1 / Q_{o}$ and an intercept of $1 / K_{L}$.
Data for Langmuir, Freundlich isotherm were plotted for adsorption of molecules into the nanoadsorbent in Figures 2(a) and 2(b). The parameters obtained from the Langmuir $\left(C_{e} / q_{e}\right.$ versus $\left.C_{e}\right)$, Freundlich $\left(\log q_{e}\right.$ versus $\left.\log C_{e}\right)$ isotherm were evaluated. Further plots for adsorption equilibriums at different temperature for $q_{e}=f\left(C_{e}\right)$ have been demonstrated in Figures 2(c) and 2(d). To compare the accuracy of the models quantitatively, the correlation coefficients $\left(R^{2}\right)$ were calculated as 0.984 (Langmuir) and 0.941 (Freundlich) whose analysis suggested that the Langmuir isotherm model furnishes a better fit to the adsorption data as compared to Freundlich model. This indicated monolayer coverage of the molecules onto the adsorbent with ach molecule having equal activation energy and that sorbate-sorbate interaction is negligible [20]. The essential features of Langmuir adsorption isotherm can be expressed in terms of a separation factor or equilibrium parameter $\left(R_{L}\right)$ which is a dimensionless constant. The $R_{L}$ value indicates the shape of the isotherm to be irreversible $\left(R_{L}=0\right)$, favourable $\left(0<R_{L}<1\right)$, linear $\left(R_{L}=\right.$ $0)$, or unfavourable $\left(R_{L}>1\right)$ [21]. The maximum uptake of pollutants by rice husk was calculated as $71.4285 \mathrm{mg} / \mathrm{g}$.

On the other hand the Freundlich isotherm [22] states that uptake occurs on a heterogeneous surface by monolayer adsorption [23] and is expressed as

$$
\log q_{e}=\log K_{f}+\left(\frac{1}{n}\right) \log C_{e},
$$

where $C_{e}$ is the equilibrium concentration, $q_{e}$ is the amount of ions or molecules adsorbed $(\mathrm{mg} / \mathrm{g})$, and $K_{f}$ and $n$ are 


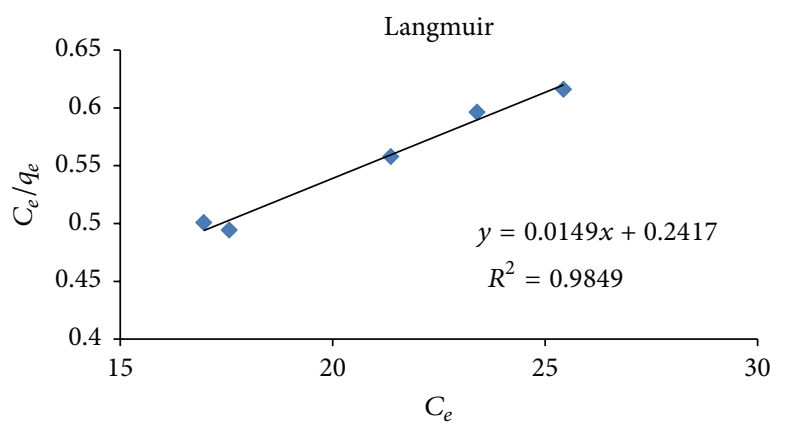

(a)

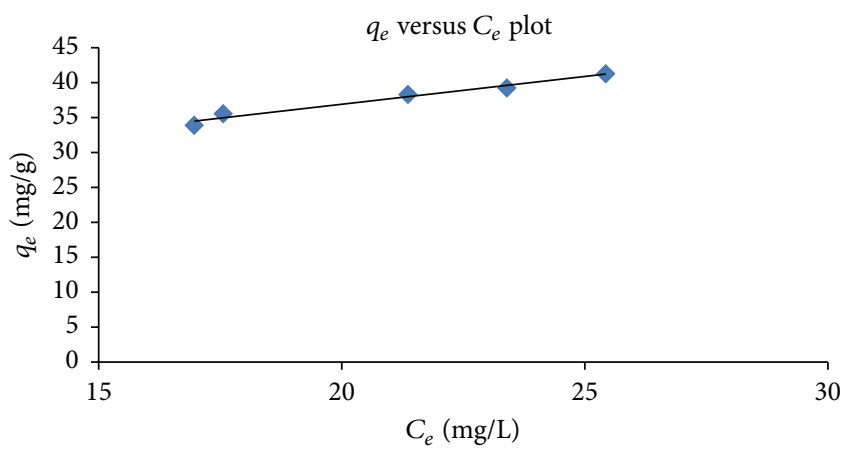

(c)

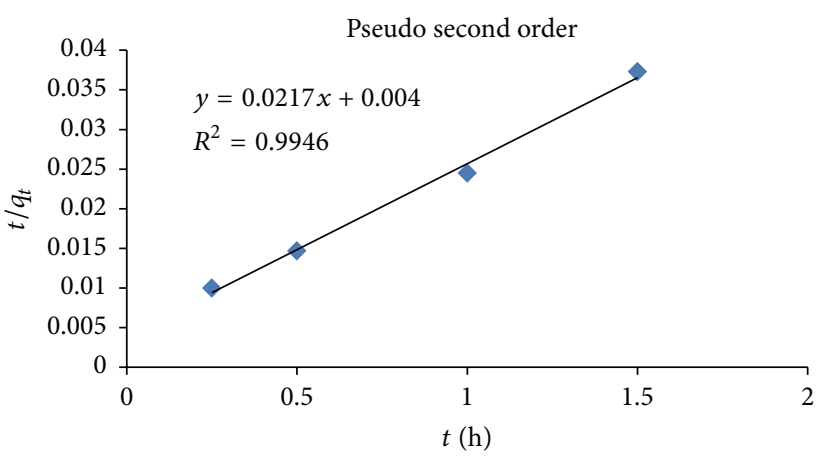

(e)

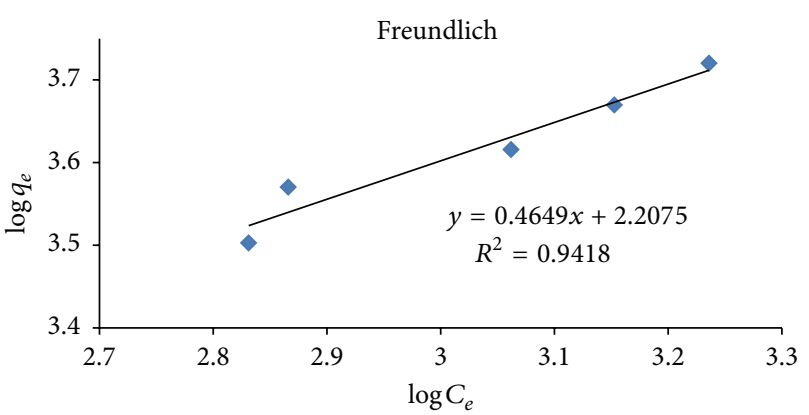

(b)

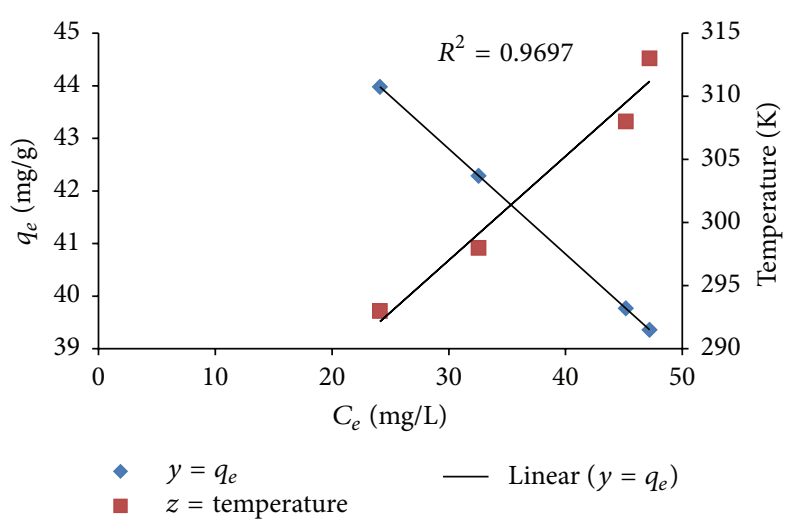

(d)

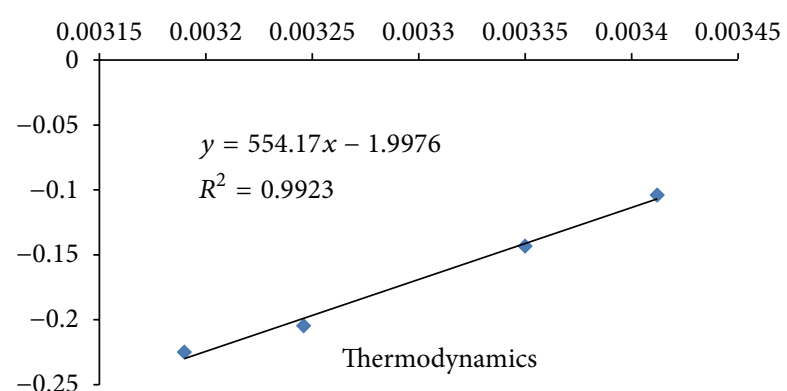

(f)

FIGURE 2: (a) Langmuir isotherm plot for adsorption onto rice husk. (b) Freundlich isotherm plot for adsorption onto rice husk. (c) Plot of $q_{e}$ versus $C_{e}$ for adsorption isotherms onto rice husk. (d) Plot of $q_{e}$ versus $C_{e}$ at different temperature for adsorption isotherms onto rice husk. (e) Pseudo-second-order kinetic model for adsorption onto rice husk. (f) Van't Hoff plot for estimation of thermodynamic parameters for adsorption onto rice husk.

Freundlich constants related to the adsorption capacity and adsorption intensity, respectively.

The Freundlich isotherm showed that the situation $n>$ $1(n=2.155)$ is often prevalent and may be due to the distribution of surface sites or any other significant factor that causes a reduction in adsorbent-adsorbate interaction with expanding surface density [24].

3.4. Adsorption Kinetics. Several kinetic models are in use to explain the mechanism of the adsorption processes in order to be able to design industrial scale separation processes. A simple pseudo-second-order equation was used:

$$
\frac{t}{q_{t}}=\frac{1}{K_{2} q_{e}^{2}}+\frac{t}{q_{e}}
$$

where $q_{t}$ and $q_{e}$ are the amount of adsorption at time $t$ and equilibrium, respectively, and $K_{2}$ denotes the rate constant of the pseudo-second-order adsorption process. 
The experimental data for the adsorption kinetics showed that it was found to be well suited with the pseudo-secondorder model. It is presented in Figure 2(e). The pseudosecond-order model constants, $K_{2}$ and $q_{e}$, were evaluated from the slope and intercept of the plots of $t / q_{t}$ versus $t$. The model parameters along with the correlation coefficient values $\left(R^{2}\right)$ as 0.994 are calculated with $q_{e}=47.6190 \mathrm{mg} / \mathrm{g}$ and $K_{2}=0.110 \mathrm{~g} \mathrm{mg}^{-1} \mathrm{~min}^{-1}$. It can be also concluded that the rate limiting step may be a chemisorption process.

3.5. Adsorption Thermodynamics. The thermodynamics of an adsorption process is obtained from a study of the influence of temperature on the process. Standard Gibbs energy was as follows:

$$
\Delta G^{\circ}=-R T \ln K_{c} .
$$

The equilibrium constant $K_{c}$ was evaluated at each temperature using the following relationship:

$$
K_{c}=\frac{C_{a}}{C_{e}} .
$$

$K_{c}$ is distribution coefficient for adsorption. $C_{a}$ is equilibrium concentration on the adsorbent. $C_{e}$ is equilibrium concentration in solution.

Other thermodynamic parameters such as change in standard enthalpy $\Delta H^{\circ}$ and standard entropy $\Delta S^{\circ}$ were determined using the following equations.

Both the values of energy and entropy are the actual indicators for practical application of a process factors in any adsorption process and engineering practice; these thermodynamic parameters should be considered in order to determine what processes will occur spontaneously. The thermodynamic parameters such as Gibbs energy $(\Delta G)$, enthalpy $(\Delta H)$, and entropy changes $(\Delta S)$ for the adsorption process can be determined using Van't Hoff equation:

$$
\begin{gathered}
\Delta G^{\circ}=\Delta H^{\circ}-T \Delta S^{\circ}, \\
\ln K_{\mathrm{eq}}=-\frac{\Delta H^{\circ}}{R T}+\frac{\Delta S^{\circ}}{R} .
\end{gathered}
$$

$\Delta G^{\circ}$ is Gibbs free energy change and $\Delta H^{\circ}$ is enthalpy of reaction.

The enthalpy change is determined graphically by plotting $\ln \left(K_{\mathrm{eq}}\right)$ versus $1 / T$ which gives a straight line and the values of $\Delta G$ and $\Delta S$ computed numerically from the slope and intercept shown in Figure 2(f) and Table 2. Gibbs energy values at $293 \mathrm{~K}, 298 \mathrm{~K}, 308 \mathrm{~K}$, are $313 \mathrm{~K}$ are negative and large and increase with increase of temperature. Furthermore, decrease in the negative value of $\Delta G$ with increasing temperature suggests that the adsorption process was more favourable at lower temperatures and thermodynamically favourable. Negative value of $\Delta H$ indicates that the process is exothermic. The value of $\Delta S$ shows the feasibility of the adsorption and the increased randomness at the sorbent/solution interface during the adsorption of molecules onto rice husk. The negative value of $\Delta S$ also suggests that the process is enthalpy dominated [25].
TABLE 2: Thermodynamic parameters for adsorption onto rice husk.

\begin{tabular}{lccc}
\hline $\begin{array}{l}\text { Temperature } \\
(\mathrm{K})\end{array}$ & $\Delta G^{\circ}(\mathrm{J} / \mathrm{mole})$ & $\Delta H^{\circ}(\mathrm{J} /$ mole $)$ & $\Delta S^{\circ}(\mathrm{J} / \mathrm{mole} \mathrm{K})$ \\
\hline 293 & -253.100 & Slope $=-554.1$ & Intercept $=-1.997$ \\
& $\Delta H=-4606.78$ & $\Delta S=-16.603$ \\
298 & -354.7883 & & \\
308 & -524.177 & & \\
313 & -585.253 & & \\
\hline
\end{tabular}

\section{Conclusion}

The present study shows that rice husk can be effectively used as adsorbent for treatment of dairy wastewater as it could bring about a removal up to $92.5 \%$ which could be achieved using an adsorbent dosage of $5 \mathrm{~g} / \mathrm{L}, \mathrm{pH}$ of 2 , and temperature of $30^{\circ} \mathrm{C}$. Moreover it is a cost-effective process since it is cheaply available raw material. The entire process was favoured at lower temperature and lower $\mathrm{pH}$ with a little adsorbent dosage. The solution $\mathrm{pH}$ controls the adsorptive-adsorbent and adsorptive-adsorptive electrostatic interactions, which can have a profound effect on the adsorption process. The organic removal was favoured at lower temperature which concluded that the process is exothermic. Thermodynamic parameters stated that the process was spontaneous and enthalpy driven. The maximum uptake of pollutants by rice husk was calculated to be $71.4285 \mathrm{mg} / \mathrm{g}$. Langmuir isotherm and pseudo-second-order models fitted best. But using of rice husk without any modification can bring several problems of COD loading when used in high dosages in industrial applications because the silica on the outer and impurities (fats and waxes) on the inner surfaces cause improper binding between the active sites and molecules. Thus future studies can be done by undergoing modification of rice husk.

\section{Conflict of Interests}

The authors declare that there is no conflict of interests regarding the publication of this paper.

\section{References}

[1] Dairy Processing Handbook/chapter 22, Dairy Effluents, http:// www.dairyprocessinghandbook.com/chapter/dairy-effluent.

[2] W. Qasim and A. V. Mane, "Characterization and treatment of selected food industrial effluents by coagulation and adsorption techniques," Water Resources and Industry, vol. 4, pp. 1-12, 2013.

[3] N. B. Singh, R. Singh, and M. M. Imam, "Waste water management in dairy industry: pollution abatement and preventive attitudes," International Journal of Science, Environment and Technology, vol. 3, no. 2, pp. 672-683, 2014.

[4] B. S. Shete and N. P. Shinkar, "Dairy industry waswater sources, characteristics, and its effects on environment," International Journal of Current Engineering and Technology, vol. 3, pp. 16111615, 2013.

[5] V. Mehta and A. Chavan, "Physico-chemical treatment of tarcontaining wastewater generated from biomass gasification 
plants," World Academy of Science, Engineering and Technology, vol. 3, no. 9, pp. 9-29, 2009.

[6] G. Crini, "Recent developments in polysaccharide-based materials used as adsorbents in wastewater treatment," Progress in Polymer Science, vol. 30, no. 1, pp. 38-70, 2005.

[7] G. Crini, "Non-conventional low-cost adsorbents for dye removal: a review, Bioresource Technology, vol. 97, no. 9, pp. 1061-1085, 2006.

[8] M. X. Loukidou, A. I. Zouboulis, T. D. Karapantsios, and K. A. Matis, "Equilibrium and kinetic modeling of chromium(VI) biosorption by Aeromonas caviae," Colloids and Surfaces A, vol. 242, no. 1-3, pp. 93-104, 2004.

[9] H. Jaman, D. Chakraborty, and P. Saha, "A study of the thermodynamics and kinetics of copper adsorption using chemically modified rice husk," Clean-Soil, Air, Water, vol. 37, no. 9, pp. 704-711, 2009.

[10] K. Y. Foo and B. H. Hameed, "Insights into the modeling of adsorption isotherm systems," Chemical Engineering Journal, vol. 156, no. 1, pp. 2-10, 2010.

[11] T. G. Chuah, A. Jumasiah, I. Azni, S. Katayon, and S. Y. T. Choong, "Rice husk as a potentially low-cost biosorbent for heavy metal and dye removal: an overview," Desalination, vol. 175, no. 3, pp. 305-316, 2005.

[12] B. S. Ndazi, S. Karlsson, J. V. Tesha, and C. W. Nyahumwa, "Chemical and physical modifications of rice husks for use as composite panels," Composites Part A: Applied Science and Manufacturing, vol. 38, no. 3, pp. 925-935, 2007.

[13] APHA, AWWA, and WEF, Standard Methods for the Examination of Water and Wastewater, American Public Health Association, Washington, DC, USA, 21st edition, 2005.

[14] R. Gong, Y. Ding, M. Li, C. Yang, H. Liu, and Y. Sun, "Utilization of powdered peanut hull as biosorbent for removal of anionic dyes from aqueous solution," Dyes and Pigments, vol. 64, no. 3, pp. 187-192, 2005.

[15] K. H. Chu and M. A. Hashim, "Removal of Copper(II) from aqueous solutions by prawn shell particles," in Proceedings of the 5th World Congress of Chemical Engineering, Melbourne, Australia, September 2001.

[16] C. Moreno-Castilla, "Adsorption of organic molecules from aqueous solutions on carbon materials," Carbon, vol. 42, no. 1 , pp. 83-94, 2004.

[17] S. Chakraborty, S. Chowdhury, and P. Das Saha, "Adsorption of Crystal Violet from aqueous solution onto $\mathrm{NaOH}$-modified rice husk," Carbohydrate Polymers, vol. 86, no. 4, pp. 1533-1541, 2011.

[18] L. J. Yu, S. S. Shukla, K. L. Dorris, A. Shukla, and J. L. Margrave, "Adsorption of chromium from aqueous solutions by maple sawdust," Journal of Hazardous Materials, vol. 100, no. 1-3, pp. 53-63, 2003.

[19] S. Chowdhury, R. Mishra, P. Kushwaha, and P. Das, "Optimum sorption isotherm by linear and nonlinear methods for safranin onto alkali-treated rice husk," Bioremediation Journal, vol. 15, no. 2, pp. 77-89, 2011.

[20] I. Langmuir, "The adsorption of gases in plane surface of glass, mica and platinum," Journal of the American Chemical Society, vol. 40, no. 9, pp. 1361-1368, 1916.

[21] K. R. Hall, L. C. Eagleton, A. Acrivos, and T. Vermeulen, "Pore- and solid-diffusion kinetics in fixed-bed adsorption under constant-pattern conditions," Industrial \& Engineering Chemistry Fundamentals, vol. 5, no. 2, pp. 212-223, 1966.

[22] H. M. F. Freundlich, "Uber die adsorption in losungen," Zeitschrift für Physikalische Chemie, vol. 57, pp. 385-470, 1906.
[23] Y. Bulut and Z. Baysal, "Removal of $\mathrm{Pb}$ (II) from wastewater using wheat bran," Journal of Environmental Management, vol. 78, no. 2, pp. 107-113, 2006.

[24] I. Vázquez, J. Rodríguez-Iglesias, E. Marañón, L. Castrillón, and M. Álvarez, "Removal of residual phenols from coke wastewater by adsorption," Journal of Hazardous Materials, vol. 147, no. 1-2, pp. 395-400, 2007.

[25] P. D. Saha, S. Chakraborty, and S. Chowdhury, "Batch and continuous (fixed-bed column) biosorption of crystal violet by Artocarpus heterophyllus (jackfruit) leaf powder," Colloids and Surfaces B: Biointerfaces, vol. 92, pp. 262-270, 2012. 

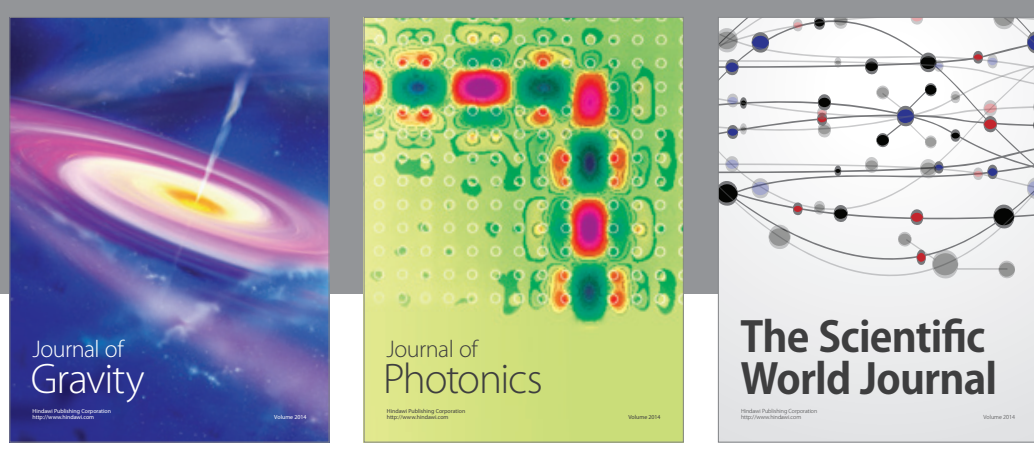

The Scientific World Journal
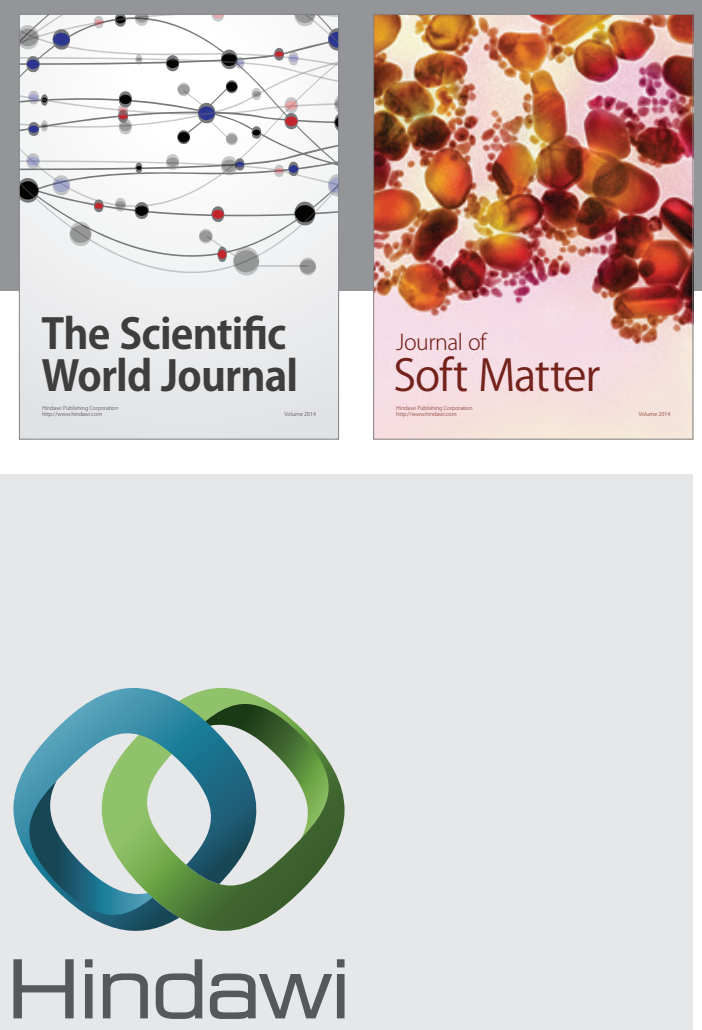

Submit your manuscripts at

http://www.hindawi.com

nternational Journal of

Statistical Mechanics
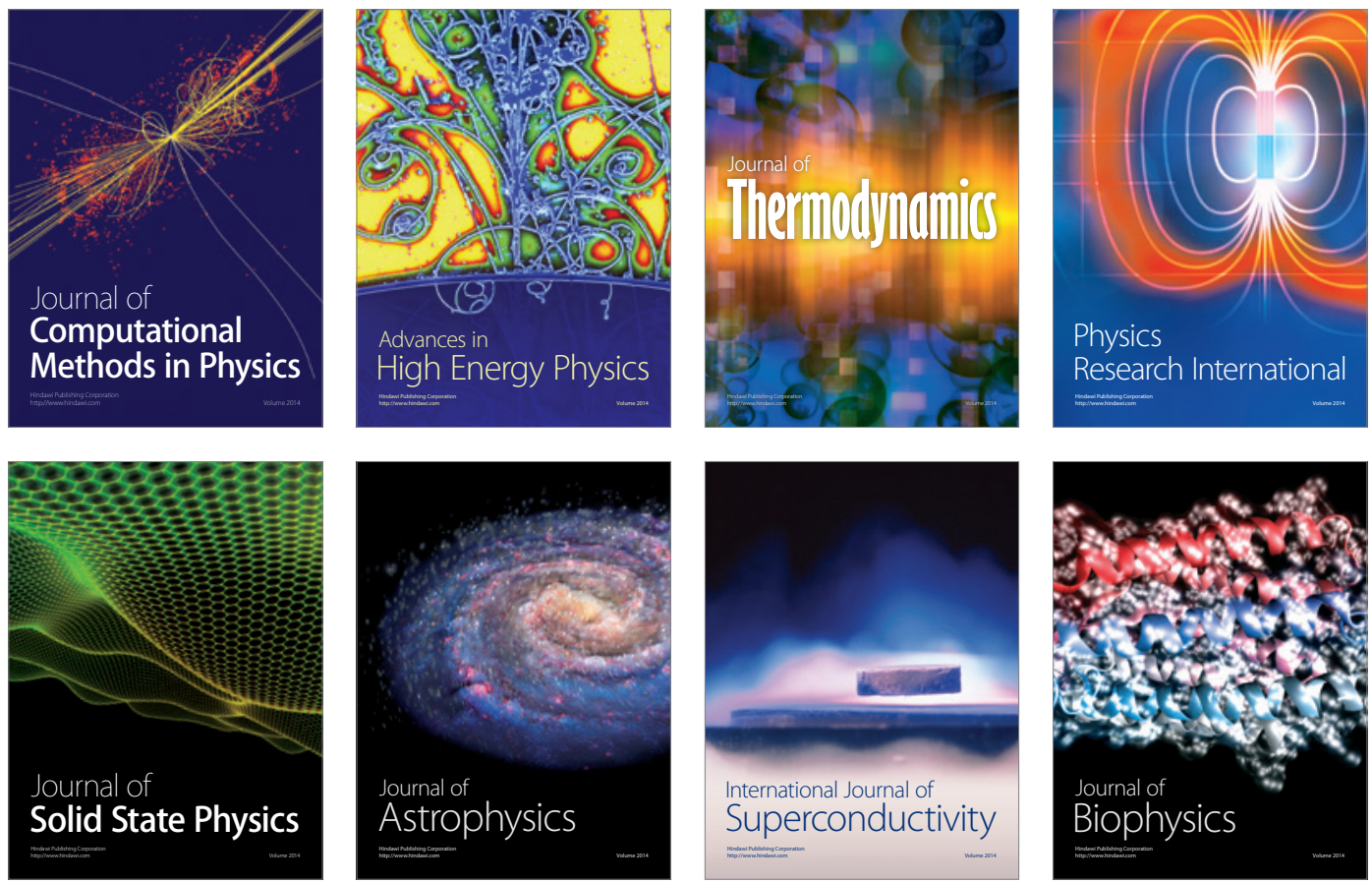
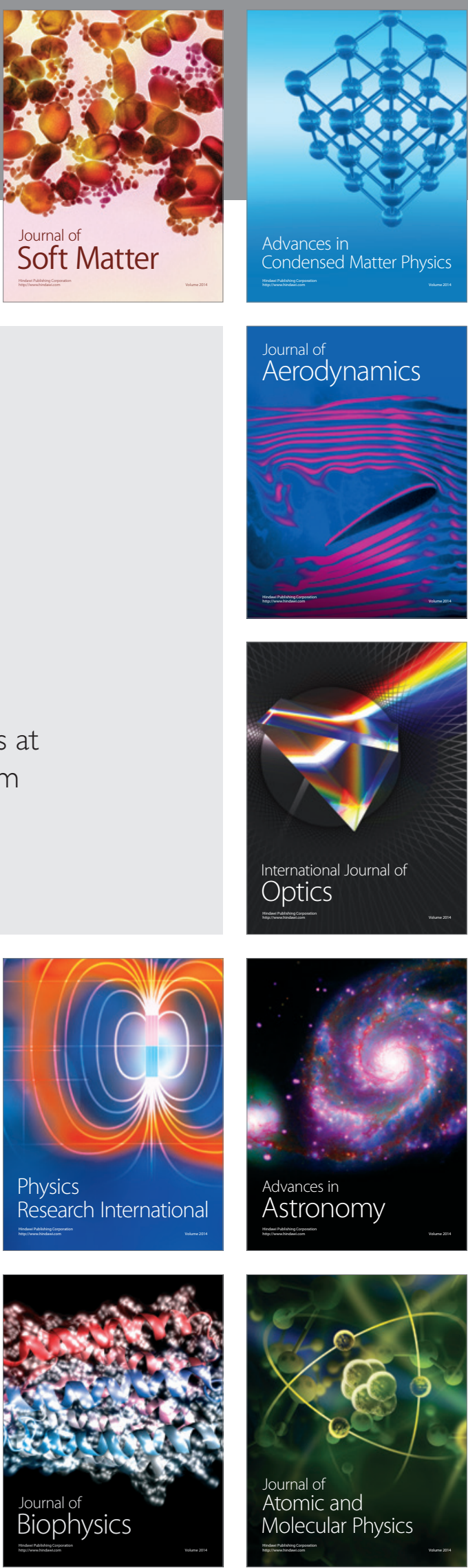